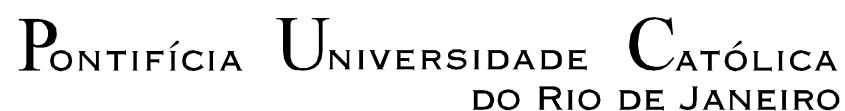

DO RIO DE JANEIRO

Leonardo Vieira de Almeida

\title{
GRANDE SERTÃO: VEREDAS: PACTO E PROMESSA
}

\section{TESE DE DOUTORADO}

Tese apresentada ao Programa de Pós-graduação em Letras da PUC-Rio como requisito parcial para obtenção do título de Doutor em Letras.

Orientadora: Prof ${ }^{a}$. Eliana Lúcia Madureira Yunes Garcia 


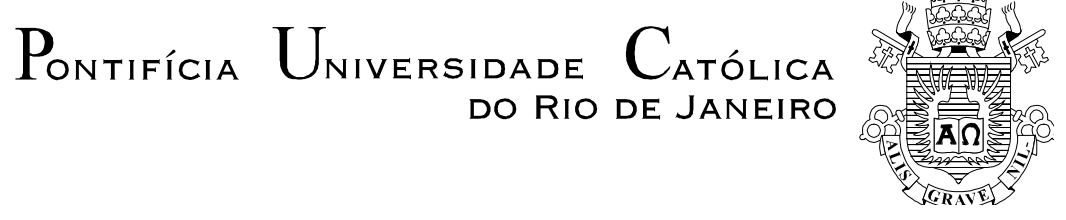

Leonardo Vieira de Almeida

GRANDE SERTÃO: VEREDAS: PACTO E PROMESSA

Tese apresentada como requisito parcial para obtenção do grau de Doutor pelo Programa de PósGraduação em Letras do Departamento de Letras do Centro de Teologia e Ciências Humanas da PUC-Rio. Aprovada pela Comissão Examinadora abaixo assinada.

Prof $^{a}$. Eliana Lúcia Madureira Yunes Garcia Orientadora Departamento de Letras - PUC-Rio

Prof ${ }^{a}$. Carlinda Fragale Pate Nuñez UERJ

Prof ${ }^{\text {a }}$ Maria Celia Barbosa Reis da Silva Universidade da Força Aérea

Prof. Marcus Alexandre Motta

UERJ

Prof. Marco Americo Lucchesi UFRJ

Prof. Paulo Fernando Carneiro de Andrade Coordenador Setorial do Centro de Teologia e Ciências Humanas - PUC-Rio

Rio de Janeiro, 19 de maio de 2010. 
Todos os direitos reservados. É proibida a reprodução total ou parcial do trabalho sem autorização da universidade, do autor e da orientadora.

\section{Leonardo Vieira de Almeida}

Graduou-se em Arquitetura e Urbanismo pela UERJ (Universidade Federal do Rio de Janeiro) em 1997. Obteve o título de mestre em Literatura Brasileira pela UERJ (Universidade do Estado do Rio de Janeiro) em 2005. Tem experiência na área de Letras, com ênfase em literatura brasileira, hispano-americana e comparada, atuando principalmente nos seguintes temas: Guimarães Rosa, literatura do sertanismo, tradição fáustica, transculturação narrativa e neobarroco na América Latina, crônicas de descobrimento da América, Machado de Assis, tradução e estudo do conto.

Ficha Catalográfica

Almeida, Leonardo Vieira de

Grande Sertão: Veredas : pacto e promessa / Leonardo Vieira de Almeida ; orientadora: Eliana Lúcia Madureira Yunes Garcia. - 2010.

141 f. : il. ; $30 \mathrm{~cm}$

Tese (Doutorado em Letras)-Pontifícia Universidade Católica do Rio de Janeiro, Rio de Janeiro, 2010.

Inclui bibliografia

1. Letras - Teses. 2. Grande Sertão: Veredas. 3. Conto. 4. Pacto com a linguagem. 5. Ficção filosófica. 6. Geografias literárias. I. Yunes, Eliana Lúcia Madureira. II. Pontifícia Universidade Católica do Rio de Janeiro. Departamento de Letras. III. Título. 
À mutuca de Sócrates, fabulista. 


\section{Agradecimentos}

Agradeço a sensibilidade e dedicação de minha orientadora, Eliana Lucia Madureira Yunes, que me ajudou, com grande afeto, a acreditar na viagem de volta e descobrir cada vez mais perguntas.

Minha homenagem toda especial a Marcus Alexandre Motta, cujo amor pela literatura e pelo contar acendeu a chama viva destes "contos".

A Jason Carneiro, cujo apoio e incentivo tornaram possível a "antiperipleia". Aos cegos de tanto ver. 


\section{Resumo}

Almeida, Leonardo Vieira de; Garcia, Eliana Lúcia Madureira Yunes. Grande Sertão: Veredas : pacto e promessa. Rio de Janeiro, 2010. 141p. Tese de Doutorado - Departamento de Letras, Pontifícia Universidade Católica do Rio de Janeiro.

Guimarães Rosa costumava dizer que só se pode falar do sertão por meio do conto ou da lenda. Considerando Grande Sertão: Veredas um grande conto, defendo a importância dessa forma como um ensaio que busca a redescoberta da Terra Nova mediante a fala de um ex-jagunço semiletrado. Se nossa História não foi forte no sentido de uma contribuição filosófica, a geografia, terra dos contos, anuncia o pensar enquanto força cujo gesto fundador se baseia no poder de pactuar com o cotidiano o nascimento da Literatura.

\section{Palavras-Chave}

Grande Sertão: Veredas, Conto, Pacto com a linguagem, Ficção Filosófica, Geografias Literárias. 


\section{Abstract}

Almeida, Leonardo Vieira de; Garcia, Eliana Lúcia Madureira Yunes. Grande Sertão : Veredas: pact and promise. Rio de Janeiro, 2010. 141p. Tese de Doutorado - Departamento de Letras, Pontifícia Universidade Católica do Rio de Janeiro.

Guimarães Rosa used to say that one can only talks about the "sertão" by means of the tale, or the legend. Considering Grande Sertão: Veredas a big-sized tale, I defend the importance of this form as an essay that seeks for the rediscovery of the New Land, by means of an illiterate, former jagunço's speech. If our History was not strong in the sense of a philosophical contribution, geography, realm of tales, announces the thinking as a force, whose founding gesture is based on the power to make a pact with the quotidian, giving birth to Literature.

\section{Keywords}

Grande Sertão: Veredas, Tale, Pact with the language, Philosophical Fiction, Literary Geographies. 


\section{Sumário}

$\begin{array}{lr}\text { 1. Prólogo } & 12\end{array}$

2. Conto 17

2.1. Conto do lugar 17

2.2.Conto da anedota 24

3. Chama 31

3.1.Conto dos provérbios 31

3.2.Conto dos causos 38

3.3.Conto das adivinhas 45

3.4.Conto dos sermões $\quad 51$

3.5.Conto Diadorim 58

3.5.1. Primeiro Retábulo $\quad 58$

3.5.2. Segundo Retábulo $\quad 60$

3.5.3. Terceiro Retábulo 61

3.6.Conto de cavalaria $\quad 65$

3.7.Conto da Lei $\quad 74$

3.8.Conto sem rosto $\quad 81$

3.9.Conto do humor $\quad 88$

3.10. Conto da Aurora 95

4. Reconto 96

4.1.Hipotrélico 102

4.2.Nós, os temulentos 107

4.3.A escova e a dúvida 114

5. Epílogo 121

6. Referências bibliográficas 122

$\begin{array}{lll}\text { 7. Anexo } & 135\end{array}$

7.1.Referências bibliográficas por conto 135 


\section{Lista de figuras}

Figura 1: segunda página do manuscrito da carta de Pero Vaz de Caminha a El-Rei D. Manuel.

Figura 2: mapa da provincia de Tabasco em Yucatán (1579).

Archivo de Indias, Sevilla.

Figura 3: ilustração de Theodore de Bry para o livro Duas viagens ao

Brasil, de Hans Staden.

Figura 4: gravura de Theodore de Bry, in Brevissima Relação da Destruição das Indias, de Frei Bartolomé de Las Casas.

Figura 5 e 6: ilustrações de Theodore de Bry gravadas para a edição latina de Frankfurt (1548) da obra de Frei Bartolomé de Las Casas. Regionum Indicarum per Hispanes quosdam devastatarum verissima.

Figura 7: gravura em cobre feita por Carolus Grandi em 1742 para o livro Vida do Apóstolico Padre Antônio Vieira, de autoria do P. ${ }^{\mathrm{e}}$ André de Barros, publicado em Lisboa em 1746.

Figura 8: gravura em metal de Theodore Galle, baseada em desenho de Jan van der Straet, representando o primeiro encontro de Vespúcio com a América, 1589.

Figura 9: frontispicio de Los quatro libros del virtuoso Caballero

Amadis de Gaula, Zaragoza, Jorge Coci, 1508.

Figura 10: De cynocephalis, aeleala, leucotrata et sciopedibus.

S. Brant, Fábulas de Esopo, fo. 179 verso. 
Figura 11: ilustração de John Gilbert para edição de $O$ Rei Lear, de William Shakespeare.

Figura 12: ilustração de Gustave Doré para edição de $O$ engenhoso fidalgo Dom Quixote de la Mancha, de Miguel de Cervantes.

Figura 13: gravura de E. Méaulle publicada no volume Christophe Colomb, de M. Ricard, Paris, Alfred Mame et Fils, Éditeurs, 1898.

Figura 14: gravura reproduzida da "Edição Comemorativa do $3^{\circ}$. Centenário da Morte de Camões”, publicação de Emilio Biel, edição de 1880.

Figura 15: carraca no porto de Mothoni, xilogravura de Bernhard von Breindenbach, 1486.

Figura 16: mulher escovando os dentes em Paris, 1889. 
Não, não sou romancista; sou um contista de contos críticos. Meus romances e ciclos de romances são na realidade contos nos quais se unem a ficção poética e a realidade.

"Diálogo com Guimarães Rosa" 